\title{
The Pharmacokinetics of Fluticasone Furoate Given Intranasally in Healthy Subjects Using an Ultra-Sensitive Analytical Assay
}

\author{
Authors \\ Mohammed Bouhajib', Zia Tayab² \\ Affiliations \\ 1 Bioanalytical Laboratory, Pharma Medica Research Inc, \\ Mississauga, Canada \\ 2 Scientific Affairs, Pharma Medica Research Inc, \\ Mississauga, Canada
}

\section{Key words}

bioavailability, pharmacokinetics, pulmonary \& respiratory pharmacology, absorption, bioanalytical method, nasal spray, Fluticasone Furoate

received $\quad 02.01 .2020$

accepted 29.04.2020

\author{
Bibliography \\ DOI https://doi.org/10.1055/a-1170-3083 \\ Drug Res 2020; 70: 310-316 \\ (c) Georg Thieme Verlag KG Stuttgart · New York \\ ISSN 2194-9379
}

Correspondence:

Zia Tayab

Scientific Affairs, Pharma Medica Research Inc

6100 Belgrave Road

Mississauga

L5R 0B7

Canada

Tel.:+ 1905624 9115, Fax: + 19056244433

ztayab@pharmamedica.com

\begin{abstract}
Purpose It has been previously shown that the complete pharmacokinetic profile, in particular the elimination phase, of intranasal fluticasone furoate has not been fully characterized due to the inability to quantify concentrations at low enough levels. This study was designed to evaluate the pharmacokinetic profile of intranasal FF using a validated, ultra-sensitive analytical method in healthy subjects.

Methods This was an open-label, single-dose, two-period, one-treatment, crossover study. A dose of $880 \mu \mathrm{g}$ fluticasone furoate was administered intra nasally. Blood samples for pharmacokinetic analysis were collected at 23 time points up to $36 \mathrm{~h}$ and analyzed for FF plasma levels using a lower limit of quantitation (LLOQ) of $0.1 \mathrm{pg} / \mathrm{mL}$. Medical and adverse events (AE) were monitored throughout the study.

Results Eighteen subjects were enrolled in and 17 completed the study. The results showed that all 17 subjects had measurable fluticasone furoate plasma concentrations at all time points with a clearly defined elimination phase, thus allowing estimation of $A \cup C_{\text {inf }}$ and $t_{1 / 2}$. Median $T_{\max }$ was $1.33 \mathrm{~h}$ (range $=0.75-6.00$ ), mean $C_{\max }$ was $13.05 \pm 7.59 \mathrm{pg} / \mathrm{mL}$, mean $\mathrm{AUC}_{\mathrm{t}}$ was $148.48 \pm 77.76 \mathrm{pg} / \mathrm{mL}^{*} \mathrm{~h}$, mean $\mathrm{AUC}_{\text {inf }}$ was $279.07 \pm 187.81 \mathrm{pg} / \mathrm{mL}^{*} \mathrm{~h}$, and mean $\mathrm{t}_{1 / 2}$ was $31.67 \pm 29.23 \mathrm{~h}$. In total 4 subjects ( $22.2 \%$ ) experienced $4 \mathrm{AEs}$.

Conclusion Using a lower LLOQ than what has been previously reported, a complete characterization of intranasal fluticasone furoate pharmacokinetics, including a clearly defined terminal elimination phase, was achieved. This method will allow for further investigations into the pharmacokinetics of fluticasone furoate.
\end{abstract}

\section{Introduction}

Fluticasone furoate is an enhanced-affinity intranasal corticosteroids (INCS) approved for the treatment of allergic rhinitis (AR) in adults and children 2 years of age and older [1]. It exhibits its antiinflammatory effect as an entire molecule and is therefore not a prodrug or a salt [2]. The exact mechanism of action of fluticasone furoate in treating AR is not full known, and may affect the early and late phase inflammatory response [3]. It is suggested that being a corticosteroid, it exhibits its anti-inflammatory effect on multiple inflammatory cells (such as, mast cells, eosinophils, neutrophils, macrophages, and lymphocytes) and mediators (such as, histamine, eicosanoids, leukotrienes, and cytokines) [1,3]. Other theories suggest that fluticasone furoate can suppress inflammatory gene activation through multiple mechanisms, such as inhibition of pro-inflammatory transcription factors like the NFKB $[2,4]$. Symptom relief can be achieved approximately $8 \mathrm{~h}$ after starting treatment and can last for up to $24 \mathrm{~h}$ [3].

Intranasal corticosteroids are considered the mainstay therapy of AR, are highly effective in treating AR-associated symptoms of nasopharyngeal itching, sneezing, rhinorrhea, and nasal congestion, help improving ocular symptoms, and are recommended to be used on a continuous basis for optimum efficacy [5-7].

To date, there is no evidence that one INCS is more clinically effective than another despite differences in potency $[5,8]$; however, 
different INCS are characterized by different pharmacological and pharmacokinetic properties [8]. It is reported that fluticasone furoate has the highest relative glucocorticoid receptor affinity and lipophilicity, an extensive hepatic first-pass metabolism, and with one of the lowest systemic exposures and potential risks among INCS used for AR [3, 8].

The systemic bioavailability of fluticasone furoate is very low $[9,10]$, with reported average oral bioavailability of $1.26 \%[9]$ and absolute bioavailability of $0.5 \%$ [10]. Following multiple doses of $800 \mu \mathrm{g}$ IN fluticasone furoate every $8 \mathrm{~h}$ for 10 days, mean $\mathrm{AUC}_{\mathrm{t}}$ was reported to be $74.92 \mathrm{pg} / \mathrm{mL}^{*} \mathrm{~h}\left(95 \% \mathrm{Cl}=43.64-128.63 \mathrm{pg} / \mathrm{mL}^{*} \mathrm{~h}\right)$, mean $C_{\max }$ was $20.53 \mathrm{pg} / \mathrm{mL}(95 \% \mathrm{Cl}=16.04-26.27 \mathrm{pg} / \mathrm{mL})$, and median was $T_{\max } 0.75 \mathrm{~h}$ (range $=0.08-8.00 \mathrm{~h}$ ). The half-life $\left(\mathrm{t}_{1 / 2}\right)$ and $A U C_{\text {inf }}$ were not derived due to lack of quantifiable concentrations at the terminal phase [10].

Fluticasone furoate was shown to be highly bound (>99\%) to plasma proteins in vitro studies, and to undergo extensive first-pass metabolism by the cytochrome P450 isozyme CYP3A4 to form the $17 \beta$-carboxylic acid metabolite via hydrolysis. Following oral and intravenous (IV) administration, fluticasone furoate was shown to be more than $90 \%$ eliminated in the feces, with minimal (1-2.6\%) urinary excretion. Following a single $250 \mu \mathrm{g} I V$ dose of fluticasone furoate showed a $t_{1 / 2}$ of $15.12 \mathrm{~h}(95 \% \mathrm{Cl}=11.82-19.35 \mathrm{~h})$, volume of distribution of $608.4 \mathrm{~L}(95 \% \mathrm{Cl}=375.4-985.8 \mathrm{~L})$, and clearance of $57.45 \mathrm{~L} / \mathrm{h}(95 \% \mathrm{Cl}=45.51-72.52 \mathrm{~L} / \mathrm{h})[1,2]$. One study reported a mean $\mathrm{AUC}_{\text {inf }}$ of $4259.39 \mathrm{pg} / \mathrm{mL}^{*} \mathrm{~h}(95 \% \mathrm{Cl}=3869.68-4688.34 \mathrm{pg} /$ $\left.\mathrm{mL}^{*} \mathrm{~h}\right), \mathrm{t}_{1 / 2}$ of $10.584 \mathrm{~h}(95 \% \mathrm{Cl}=7.713-14.525 \mathrm{~h})$, mean $\mathrm{AUC}_{\mathrm{t}}$ of $3787.47 \mathrm{pg} / \mathrm{mL}^{*} \mathrm{~h}\left(95 \% \mathrm{Cl}=3478.52-4123.86 \mathrm{pg} / \mathrm{mL}^{*} \mathrm{~h}\right)$, mean $\mathrm{C}_{\max } 6652.10 \mathrm{pg} / \mathrm{mL}(95 \% \mathrm{Cl}=5803.01-7625.43 \mathrm{pg} / \mathrm{mL})$, volume of distribution at steady state of $361.7 \mathrm{~L}(95 \% \mathrm{Cl}=264.8-494.0 \mathrm{~L})$, clearance of $58.70 \mathrm{~L} / \mathrm{h}(95 \% \mathrm{Cl}=53.33-64.60 \mathrm{~L} / \mathrm{h})$, and median $\mathrm{T}_{\max }$ of $0.29 \mathrm{~h}$ (range $=0.08-0.33 \mathrm{~h}$ ), following a single $250 \mu \mathrm{g} \mathrm{IV}$ dose of fluticasone furoate [10].

Previous studies have shown that fluticasone furoate plasma levels measured using a lower limit of quantitation (LLOQ) of $10 \mathrm{pg} /$ $\mathrm{mL}$ were mostly undetectable (below the limit of quantitation [BLQ]), except when IV or supra-therapeutic IN doses were used, and that the elimination phase could not be characterized following IN administration due to unquantifiable concentrations during the terminal phase [9-11]. This study was designed to evaluate the pharmacokinetic profile of fluticasone furoate using a validated analytical method with a lower LLOQ, after a single dose in healthy subjects.

\section{Methods}

\section{Study design}

This was an open-label, single-dose, one-treatment, crossover study conducted at Pharma Medica Research Inc., Saint Charles, Missouri, USA. The crossover design was chosen to determine the intra-subject coefficient of variation of fluticasone furoate (results not shown). The results of the study are presented summarizes the pharmacokinetics of fluticasone furoate. Due to the exploratory nature of this study, a planned sample size of 18 subjects was deemed appropriate.
Previous reports have shown that at lower doses, there were a very low number of samples with quantifiable fluticasone furoate concentrations [11]. A dose of $880 \mu \mathrm{g}$ was chosen for this study as it was deemed to be a reliable and safe dose to estimate fluticasone furoate bioavailability and pharmacokinetic profile $[1,2,10,11]$.

One formulation of fluticasone furoate nasal spray (from GSK Consumer Healthcare, USA) containing $27.5 \mu \mathrm{g}$ per spray was used in both periods. Each subject received one total dose of $880 \mu \mathrm{g}$ fluticasone furoate as 2 sprays in alternating nostrils until 16 sprays had been delivered in each nostril within approximately $2 \mathrm{~min}$. Subjects were given approximately 5-8 seconds to sniff or deeply inhale through their nose after every two sprays, when alternating between each nostril. The time of the first spray was considered the time of drug administration. The 2 periods were separated by a washout of 7 days between drug administrations.

Subjects remained at the clinic for approximately $10 \mathrm{~h}$ before and $24 \mathrm{~h}$ after drug administration and fasted for approximately $10 \mathrm{~h}$ before and $4 \mathrm{~h}$ after drug administration. Water was restricted from $1 \mathrm{~h}$ before until $1 \mathrm{~h}$ after drug administration. From screening to end-of-study (EOS), the planned duration of the study was up to 37 days.

\section{Study participants}

Non-smoking male and female subjects were eligible for this study if they were 18 years of age or older, had a body mass index (BMI) of $18.0-33.0 \mathrm{~kg} / \mathrm{m}^{2}$, inclusive, were healthy with no clinically significant findings from medical history, 12-lead electrocardiogram (ECG), laboratory evaluation, physical examination, and vital signs measurements, and were willing to use acceptable effective methods of contraception.

Subjects were excluded from participation if they mainly: had a known history or presence of clinically significant diseases (including conditions compromising nasal absorption such as chronic postnasal drip, epistaxis, nasal ulcer, sores, surgery, or trauma, chronic sinusitis, or significantly abnormal nasal passage), infection, or any hypersensitivity to fluticasone or related drug substances; were pregnant or lactating females; had recently participated in other clinical trial and/or donated or lost whole blood within the safe acceptable timeframe; had known history or suspected presence of tuberculosis; showed any positive serology test, urine screen test, or breath alcohol test results; used inhibitors or inducers of hepatic drug metabolism or drugs that alter gastrointestinal $\mathrm{pH} /$ movement within 30 days prior to drug administration. Subjects received financial compensation for their participation.

\section{Study endpoints}

The primary endpoint of this study was to characterize the pharmacokinetics of fluticasone furoate using our validated analytical method with a low LLOQ following the administration of a single intra-nasal dose in healthy subjects. The secondary objective was to assess safety and tolerability of fluticasone furoate.

\section{Sample collection for pharmacokinetic evaluation}

In each period, a blood sample for pharmacokinetic analysis was collected by direct venipuncture in a $10-\mathrm{mL}$ tube containing $\mathrm{K}_{2}$ EDTA as the anticoagulant, before drug administration and at $5,10,15,20,30$, and $45 \mathrm{~min}$, and at $1 \mathrm{~h}, 1 \mathrm{~h} 20 \mathrm{~min}, 1 \mathrm{~h} 40 \mathrm{~min}$, 
2h, $2 \mathrm{~h} 20 \mathrm{~min}, 2 \mathrm{~h} 40 \mathrm{~min}$, and 3, 4, 5, 6, 8, 10, 12, 16, 24, and $36 \mathrm{~h}$ after drug administration.

Whole blood samples were centrifuged at approximately $4^{\circ} \mathrm{C}$ for approximately $10 \mathrm{~min}$ at $3000 \mathrm{rpm}$ within $60 \mathrm{~min}$ of collection. The separated plasma was divided into 2 approximately equal aliquots (using the second aliquot as backup) in labeled polypropylene tubes. The plasma aliquots were stored at $-80 \pm 15^{\circ} \mathrm{C}$ within $60 \mathrm{~min}$ of whole blood collection, pending assay, and shipped on dry ice to the bioanalytical laboratory of Pharma Medica Research Inc., Ontario, Canada.

\section{Bioanalytical method and procedures}

At the bioanalytical facility, the plasma samples were analyzed for fluticasone furoate, using fluticasone furoate- $d_{5}$ as the internal standard. The standard calibration range was $0.100-100 \mathrm{pg} / \mathrm{mL}$ using a plasma sample volume of $0.800 \mathrm{~mL}$. The concentration of the internal standard was $300 \mathrm{pg} / \mathrm{mL}$. Plasma samples, treated with $\mathrm{K}_{2}$ EDTA as the anticoagulant, were processed by liquid-liquid extraction with Methyl-tert-Butyl-Ether (MtBE):Hexane (60:40), the organic phase was dried and the reconstituted sample was transferred for analysis. Samples were analyzed by LC-MS/MS (Shimadzu Prominence UFLC \& SCIEX API 6500) and reverse phase chromatography under gradient conditions with mobile phases composed of $0.01 \%$ Ammonium Hydroxide in Water and Methanol (100\%). Chromatographic separation was achieved using serial analytical columns $(C 18,50 \times 3 \mathrm{~mm}, 2.6 \mu \mathrm{m}$ and Biphenyl, $50 \times 3 \mathrm{~mm}, 2.6 \mu \mathrm{m})$. Fluticasone furoate was analyzed using positive ion scan mode and a parent-daughter mass to charge ion transition of 539-293 and 544-293 for the internal standard. The retention time for fluticasone furoate was approximately $3.3 \mathrm{~min}$.

Correlation was obtained between peak area ratios and the corresponding calibration standard concentrations over the entire calibration range. A linear equation $(y=a x+b)$ with $1 / x^{2}$ weighting

- Table 1 Accuracy and Precision of the Validated Analytical Method.

\begin{tabular}{|l|c|l|}
\hline & Precision (\%) & Accuracy (\%) \\
\hline LLOQ intra-day & $\leq 14.4$ & $84.7-111.0$ \\
\hline LLOQ inter-day & 14.4 & 101.0 \\
\hline QC L, M, H intra-day & $\leq 6.4$ & $94.3-112.0$ \\
\hline QC L, M, H inter-day & $\leq 7.2$ & $101.0-102.3$ \\
\hline
\end{tabular}

QC quality control, H high $(80 \mathrm{pg} / \mathrm{mL}), \mathrm{L}$ low $(0.3 \mathrm{pg} / \mathrm{mL})$, LLOQ lower limit of quantitation $(0.1 \mathrm{pg} / \mathrm{mL}), \mathrm{M}$ medium $(50 \mathrm{pg} / \mathrm{mL})$.

- Table 2 Stability of Fluticasone Furoate in Human Samples.

\begin{tabular}{|l|l|}
\hline Condition & Stability \\
\hline In whole blood & $3.00 \mathrm{~h}$ at room temperature \\
\hline \multicolumn{2}{|l}{} \\
\hline In plasma & $3.00 \mathrm{~h}$ in ice-water bath \\
\hline Freeze-thaw & Four cycles at $-80 \pm 15^{\circ} \mathrm{C}$ \\
\hline Bench top & $19.00 \mathrm{~h}$ at room temperature \\
\hline \multicolumn{2}{|l}{} \\
\hline Processed samples & $20.00 \mathrm{~h}$ in ice-water bath \\
\hline Autosampler & $145.25 \mathrm{~h}$ at approximately $5^{\circ} \mathrm{C}$ \\
\hline Storage of reconstituted samples & $45.00 \mathrm{~h}$ at approximately $5^{\circ} \mathrm{C}$ \\
\hline Storage of evaporated samples & $2.50 \mathrm{~h}$ at room temperature \\
\hline
\end{tabular}

was used. The coefficients of determination of the single-point calibration curves were $\geq 0.999$. The recoveries of fluticasone furoate and the internal standard were $93.7-94.1 \%$ and $92.1-95.2 \%$, respectively. The accuracy and precision of the method are presented in $>$ Table 1 and the stability of fluticasone furoate in human samples is presented in $>$ Table 2 .

\section{Safety evaluation}

Physical examination, vital signs (blood pressure, heart rate, respiratory rate, and temperature) measurements, and clinical laboratory tests (biochemistry, hematology, and urinalysis) were performed at screening and EOS. Serology blood tests (human immunodeficiency virus, hepatitis $C$ antibody, and hepatitis B surface antigen), 12-lead ECG recording, serum human chorionic gonadotropin (hCG) test for female participants, urine drug screen, urine cotinine test, and tuberculosis questionnaire evaluation were also obtained at screening. In addition, in each period, urine drug screen, urine cotinine test, urine hCG test for female participants, and breath alcohol tests were performed at check-in, blood pressure and heart rate were measured prior to drug administration and at 1,3 , and $6 \mathrm{~h}$ post-dose, and temperature was measured daily during confinement. All clinical laboratory tests were performed by Quest Diagnostics Lenexa, Kansas, USA.

The use of herbal products, nutritional supplements, vitamins, grapefruit and grapefruit-containing products, alcohol and alcohol-containing products, caffeine- and xanthine-containing products, and inhalers-, nasal sprays-, or steam inhalation-based practices were restricted during the study. Concomitant medications were not allowed during the study unless requested or approved by the investigator. Nondrug therapies that did deviate from protocol procedures were allowed. Medical and adverse events (AE) were monitored from screening to EOS.

\section{Pharmacokinetic and statistical analysis}

The pharmacokinetic parameters were estimated for fluticasone furoate using a non-compartmental approach in Phoenix WinNonlin version 6.4 (Certara USA, Inc., Princeton, NJ). The actual postdose sample collection times were used in the pharmacokinetic analysis. The peak concentration $\left(C_{\max }\right)$ and the time to reach $C_{\max }$ $\left(T_{\max }\right)$ were determined from individual plasma concentration-time profiles for FF. The area under the plasma concentration-time curve $\left(A \cup C_{t}\right)$ was calculated using the linear up-log down trapezoidal method from 0 to $36 \mathrm{~h}$. The area under the plasma concentrationtime curve from zero to time infinity $\left(A \cup C_{\text {inf }}\right.$ ) was calculated as $\mathrm{AUC}_{\mathrm{t}}+\mathrm{C}_{\mathrm{t}} / \mathrm{k}_{\mathrm{el}}$, where $C_{\mathrm{t}}$ is the last measurable concentration and $\mathrm{k}_{\mathrm{el}}$ is the terminal rate constant. The terminal half-life $\left(t_{1 / 2}\right)$ was calculated as $0.693 / \mathrm{k}_{\mathrm{el}}$. All obtained samples were assayed; however, subjects with sufficient data to allow pharmacokinetic characterization were included in the pharmacokinetics and statistical analyses. Descriptive statistics for the pharmacokinetic parameters of fluticasone furoate were calculated. Safety and tolerability of FF were assessed using descriptive statistics for all subjects who participated in the study and were primarily based on the occurrence and severity of $\mathrm{AE}$. 


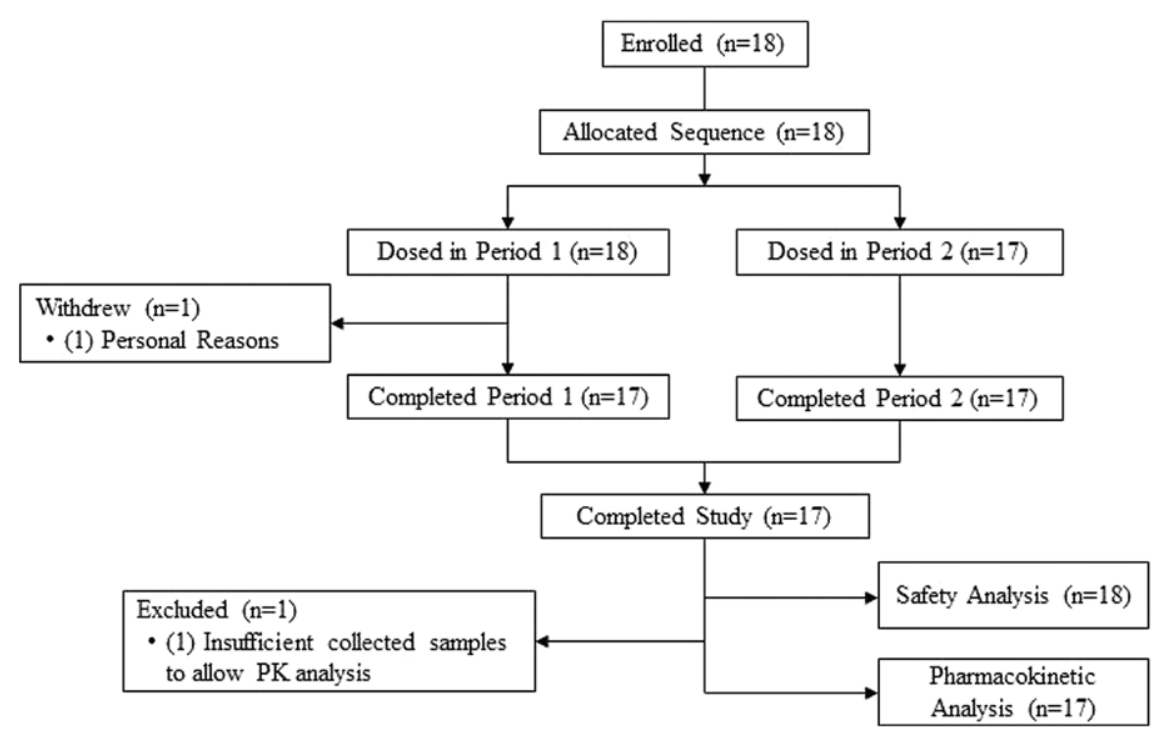

Fig. 1 Subjects disposition.

- Table 3 Summary of Demographic Characteristics.

\begin{tabular}{|l|l|}
\hline Demographics & Study Population $\mathbf{N}=\mathbf{1 8}$ \\
\hline Gender, $\mathrm{n}(\%)$ & \\
\hline Female & $11(61.1)$ \\
\hline Male & $7(38.9)$ \\
\hline Age, years, mean \pm SD (range) & $40.5 \pm 12.4(22-59)$ \\
\hline BMI, $\mathrm{kg} / \mathrm{m}^{2}$, mean \pm SD (range) & $26.5 \pm 3.6(19.6-31.4)$ \\
\hline Weight, $\mathrm{kg}$, mean $\pm \mathrm{SD}$ (range) & $76.9 \pm 12.3(155.8-183.6)$ \\
\hline Height, $\mathrm{cm}$, mean $\pm \mathrm{SD}$ (range) & $170.2 \pm 7.9(56.1-101.9)$ \\
\hline Race, $\mathrm{n}(\%)$ & \\
\hline White & $8(44.4)$ \\
\hline Black or African American & $10(55.6)$ \\
\hline Ethnicity, $\mathrm{n}$ (\%) & $0(0.0)$ \\
\hline Hispanic or Latino & $18(100.0)$ \\
\hline Not Hispanic or Latino & \\
\hline Arithmetic means are reported in this table. BMI body mass index, \\
SD standard deviation.
\end{tabular}

\section{Results}

\section{Subjects' disposition and demographics}

Eighteen healthy subjects were enrolled in and 17 subjects completed the study ( $\triangleright$ Fig. 1). Overall, 11 female and 7 male subjects participated in the study. The subjects had a mean age of 40.5 years and $\mathrm{BMI}$ of $26.5 \mathrm{~kg} / \mathrm{m}^{2}$. Eight (44.4\%) subjects were white and 10 (55.6\%) were black or African American ( $\triangleright$ Table 3).

\section{Pharmacokinetic analysis}

A total of 23 samples were collected from each of the 18 subjects. One subject withdrew from the study approximately 10 min after dosing due to personal reasons (difficult phlebotomy), and was thus excluded from the pharmacokinetic and statistical analyses. All the remaining samples collected from the 17 subjects had measurable fluticasone furoate plasma concentrations, including concentrations during the elimination phase. As such, all the 17 subjects showed concentration-time profiles with a clearly defined terminal elimination phase and so the $A \cup C_{\text {inf }}$ and $t_{1 / 2}$ could be confidently estimated.

\section{Bioanalytical analysis}

The concentrations of all the samples analyzed were within the validated range. A calibration standard and quality control samples of at least $6 \%$ of the total study samples at three different concentrations were extracted and analyzed within each batch. All seven extracted batches during the entire study conduct passed the acceptance criteria. The inter-day precision ( $\% \mathrm{CV}$ ) was $\leq 5.6 \%$ and accuracy was $91.8 \%$ to $101.6 \%$. A total of 782 samples were analyzed in this study (391 samples in period 1), of which 79 samples were randomly selected around the $C_{\max }$ and the elimination phase of each profile for incurred sample reanalysis (ISR). The results of the ISR showed $96.4 \%$ confirmation of the original values within $\pm 20 \%$.

\section{Statistical results}

Following a single $880 \mu \mathrm{g}$ dose of IN fluticasone furoate, median $\mathrm{T}_{\max }$ was $1.33 \mathrm{~h}$ (range $=0.75-6.00 \mathrm{~h}$ ), mean $C_{\max }$ was $13.05 \pm$ $7.59 \mathrm{pg} / \mathrm{mL}$, mean $A U C_{\mathrm{t}}$ was $148.48 \pm 77.76 \mathrm{pg} / \mathrm{mL}^{*} \mathrm{~h}$, mean $A U C_{\text {inf }}$ was $279.07 \pm 187.81 \mathrm{pg} / \mathrm{mL}^{*} \mathrm{~h}$, and mean $\mathrm{t}_{1 / 2}$ was $31.67 \pm 29.23 \mathrm{~h}$ ( $\triangleright$ Table 4, $>$ Fig. 2). The intra-subject variability was estimated to be $22 \%$ for $A U C_{t}$ and $24 \%$ for $C_{\max }$.

\section{Safety and tolerability}

The administration of $880 \mu \mathrm{g}$ of IN FF under fasted conditions was well tolerated by the healthy subjects who participated in the study. Four subjects (22.2\%) experienced 4 AEs in total: 3 subjects ( $16.7 \%$ ) experienced $3 \mathrm{AEs}$ (one venipuncture site reaction and 2 headache events) in period 1 and one subject (5.6\%) experienced $1 \mathrm{AE}$ 
- Table 4 Pharmacokinetic Parameters Based on Plasma Fluticasone Furoate Following Administration of Single Intranasal Dose of $880 \mu \mathrm{g}$ to Healthy Subjects.

\begin{tabular}{|l|l|l|}
\hline PK Parameter & $\mathbf{N}$ & Mean \pm SD \\
\hline $\mathrm{AUC}_{\text {inf }}, \mathrm{pg} / \mathrm{mL}^{*} \mathrm{~h}$ & 17 & $279.07 \pm 187.81$ \\
\hline $\mathrm{AUC}_{\mathrm{t}}, \mathrm{pg} / \mathrm{mL}^{*} \mathrm{~h}$ & 17 & $148.48 \pm 77.76$ \\
\hline $\mathrm{C}_{\max }, \mathrm{pg} / \mathrm{mL}$ & 17 & $13.05 \pm 7.59$ \\
\hline $\mathrm{t}_{1 / 2}, \mathrm{~h}$ & 17 & $31.67 \pm 29.23$ \\
\hline & & Median (Range) \\
\hline $\mathrm{T}_{\max }, \mathrm{h}$ & 17 & $1.33(0.75-6.00)$ \\
\hline
\end{tabular}

Arithmetic means are reported in this table. $\mathrm{AUC}_{\text {inf }}$ area under the concentration versus time curve from time zero to infinity, $A \cup C_{t}$ area under the concentration versus time curve, from time zero to the time of the last measurable concentration ( $t), C_{\max }$ maximum measured concentration over the sampling period, PK pharmacokinetic, SD standard deviation, $\mathrm{t}_{1 / 2}$ apparent elimination half-life, $\mathrm{T}_{\max }$ time of the maximum measured concentration over the sampling period.

(venipuncture site reaction) in period 2. In total, the 2 headache AEs reported by 2 subjects ( $11.1 \%$ in period 1 were considered to be possibly related to FF. All AEs were mild in severity and resolved.

There were no AE-related withdrawals or serious AEs reported in this study. There were no clinically meaningful trends in laboratory safety measurements, vital signs, physical examinations, or ECGs reported during this study. All measurements were either within normal range or were deemed by the investigator to be not clinically significant for all subjects.

\section{Discussion}

With an increase in the development of newer drugs and dosage forms, a full understanding of their pharmacokinetics is essential in characterizing their disposition. The development of newer analytical methods that can quantify concentrations at lower thresholds (i. e. having a low LLOQ) plays an important role. The lack of a sensitive enough LLOQ poses a barrier in being able to confidently evaluate the complete pharmacokinetic behaviour of these drugs.

Fluticasone furoate is one of the newest INCS, is available as prescription or over-the-counter medicine, and may be more preferred by patients compared to other INCS [12]. It is one of the first-line treatments recommended in AR treatment [13-15]. Previous pharmacokinetic characterization of IN fluticasone furoate was based on an LLOQ of $10 \mathrm{pg} / \mathrm{mL}[1,9-11,16]$, rendering plasma levels at the terminal elimination phase undetectable resulting in a limited amount of pharmacokinetic information that can be obtained.

A dose escalation study involving the administration of IN fluticasone furoate over a dose range of $55-440 \mu$ g once daily for 2 weeks, showed that from 1476 plasma samples collected from 502 patients, 12 years of age or older with seasonal AR, only $5.3 \%$ of total samples from $11.8 \%$ of patients had detectable fluticasone furoate levels when an LLOQ of $10 \mathrm{pg} / \mathrm{mL}$ was used. In addition, with higher doses, more samples had quantifiable concentrations, but did not exceed $15.4 \%$ of the samples collected at the $440 \mu \mathrm{g}$ dose nor three times the LLOQ [11]. Furthermore, following the administration of a multiple-dose IN fluticasone furoate regimen of $2640 \mu \mathrm{g}$ daily for 3 days followed by $880 \mu \mathrm{g}$ on the day of PK sam-
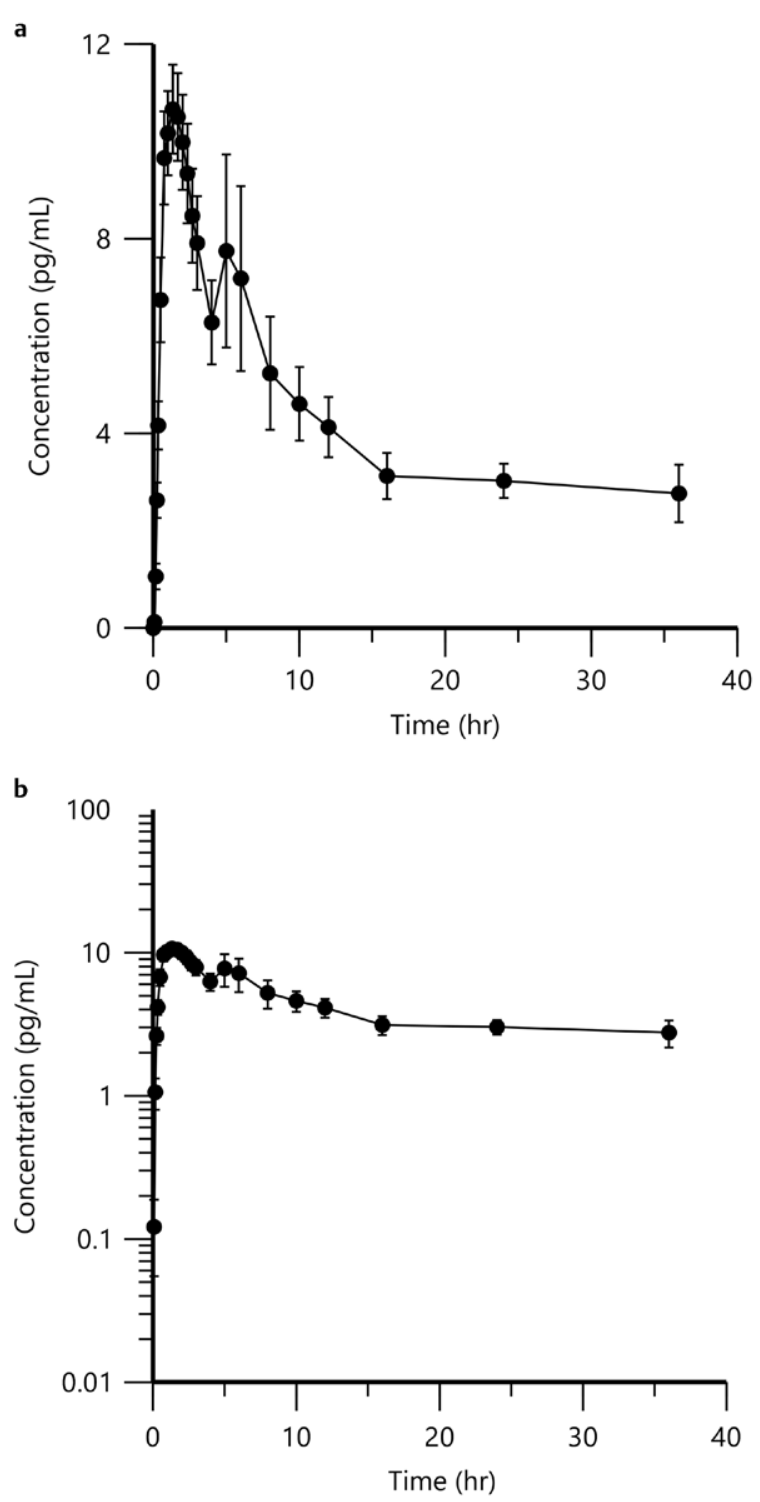

Fig. 2 Mean plasma fluticasone furoate concentration-Time profiles in linear (a) and log-linear scale (b) following administration of a single intranasal dose to healthy subjects. Error bars represent the standard deviation about the mean.

pling to 16 healthy subjects, $50.00 \%$ of subjects had BLQ plasma concentrations at $8 \mathrm{~h}$ post-dose, $6.25 \%$ had BLQ plasma concentrations at all time points, and $6.25 \%$ had only 1 measurable plasma concentration [10].

This study implemented a validated analytical method able to measure fluticasone furoate plasma concentrations using an LLOQ of $0.1 \mathrm{pg} / \mathrm{mL}$ following administration of a single $880 \mu \mathrm{g}$ dose of IN fluticasone furoate. As a result, all the samples (100.00\%) collected from all the subjects who completed the study had detectable and quantifiable plasma levels of FF at all collection time points, including the terminal linear phase, and as such allowed for a better characterization of the pharmacokinetic profile of fluticasone furoate than before. The results showed that sampling for a longer time would likely have led to more measurable concentrations, thus 
allowing for a more complete evaluation of the terminal pharmacokinetic parameters.

The results showed a higher mean $\mathrm{AUC}_{\mathrm{t}}\left(148.48 \mathrm{pg} / \mathrm{mL}^{*} \mathrm{~h}\right)$ and median $T_{\max }(1.33 \mathrm{~h})$, and lower $C_{\max }(13.05 \mathrm{pg} / \mathrm{mL})$ compared to previously reported values for IN fluticasone furoate $(74.92 \mathrm{pg} /$ $\mathrm{mL}^{*} \mathrm{~h}, 0.75 \mathrm{~h}$, and $20.53 \mathrm{pg} / \mathrm{mL}$, respectively) [10]. The $\mathrm{T}_{\max }$ range $(0.75$ to $6.00 \mathrm{~h})$ fell within previously reported values for IN fluticasone furoate $(0.08$ to $8.00 \mathrm{~h}$ ) [10]. Differences in these parameters values can be explained by the number of measurable concentrations used to calculate them owing to the LLOQ used in the analytical method. When an LLOQ of $10 \mathrm{pg} / \mathrm{mL}$ was used, $\mathrm{C}_{\max }$ and $\mathrm{T}_{\max }$ were derived from 15 subjects with at least 2 measurable plasma concentrations, including 1 subject with only 1 measurable plasma concentration, and $\mathrm{AUC}_{\mathrm{t}}$ was derived from 14 subjects with at least 2 measurable plasma concentrations, including several subjects with undetectable plasma concentrations at $8 \mathrm{~h}$ post-dose [10]. In this study, however, $C_{\max }, T_{\max }$, and $A \cup C_{t}$ were calculated based on data from 17 subjects who had all their plasma concentrations quantifiable at all pharmacokinetic sampling time points, using a 100 times lower lower limit of quantitation.

This study provides a breakthrough in the bioanalysis and pharmacokinetics of fluticasone furoate given intra-nasally. It allowed for a more accurate characterization of the concentration-time profile of fluticasone furoate following a single intra-nasal dose in healthy subjects, such that the terminal elimination phase was clearly defined allowing for a more confident estimation of $A_{U C} C_{\text {inf }}$ and $t_{1 / 2}$. In addition, the new method eliminates the need to expose healthy subjects to multiple doses and allows calculation of the pharmacokinetic parameters following a single dose even as low as $110 \mathrm{mcg}$, which corresponds to the standard dose that is given clinically.

\section{Conclusion}

Using a lower limit of quantitation of $0.1 \mathrm{pg} / \mathrm{mL}$, the complete characterization of fluticasone furoate pharmacokinetics, including a clearly defined terminal elimination phase, was achieved following a single dose given intranasally. The improved bioanalytical method enabled further insight into the pharmacokinetics of fluticasone furoate that was not possible with other analytical methods that used a higher lower limit of quantitation. With this new proven sensitivity, it will allow for more optimal study designs investigating intra-nasal or inhaled formulations of fluticasone furoate as the expected concentrations following both routes of adminstration are expected to be low. This improved bioanalytical method with allow for further investigations into the pharmacokinetics of fluticasone furoate.

\section{Authors Contributions}

MB contributed to the study concept and the bioanalytical method development and validation. ZT contributed to the study design, pharmacokinetic and statistical data analyses, study results interpretation, and writing of the initial drafts of the article. MB and ZT have reviewed and approved the final manuscript for submission, and MB holds the final responsibility of the article submission.

\section{Funding}

This study was sponsored and funded by Pharma Medica Research Inc.

\section{Compliance with Ethical Standards}

This study was approved by Salus Institutional Review Board (IRB), Texas, USA. All study procedures involving human participants were conducted in conformance with the 1964 Declaration of Helsinki and its later amendments, the International Council for Harmonisation (ICH) Good Clinical Practice (GCP) regulations, IRB ethical standards, the United States standards and requirements and other statutes or regulations regarding the protection of the rights and welfare of human subjects participating in biomedical research. All subjects provided written informed consent before trial initiation.

\section{Data Availability Statement}

The datasets generated during and/or analyzed during the current study are available from the corresponding author on reasonable request.

\section{Acknowledgments}

The authors acknowledge the role of Fida Drouby for assisting in the preparation of the manuscript.

\section{Conflict of Interest}

The authors declare that they have no conflict of interest.

\section{References}

[1] GlaxoSmithKline (2015) Avamys (fluticasone furoate nasal spray) product monograph; https://pdf.hres.ca/dpd_pm/00031850.PDF, accessed 29 December 2019

[2] European Medicines Agency (2008) Scientific discussion of Allergic Rhinitis; http://www.ema.europa.eu/docs/en_GB/document_library/ EPAR_-_Scientific_Discussion/human/000770/WC500028817.pdf, accessed 29 March 2018

[3] Anolik R. Fluticasone furoate nasal spray: Profile of an enhanced-affinity corticosteroid in treatment of seasonal allergic rhinitis. J Asthma Allergy 2010; 3: 87-99

[4] Kariyawasam HH, Scadding GK. Seasonal allergic rhinitis: Fluticasone propionate and fluticasone furoate therapy evaluated. J Asthma Allergy 2010; 3: 19-28

[5] Sur DK, Plesa ML. Treatment of allergic rhinitis. Am Fam Physician 2015; 92: 985-992

[6] Seidman MD, Gurgel RK, Lin SY et al. Clinical practice guideline: Allergic rhinitis executive summary. Otolaryngol Head Neck Surg 2015; 152: 197-206. https://doi.org/10.1177/0194599814562166

[7] Dykewicz MS, Wallace DV, Baroody F et al. Treatment of seasonal allergic rhinitis: An evidence-based focused 2017 guideline update. Ann Allergy Asthma Immunol 2017; 119: 489-511.e41. https://doi. org/10.1016/j.anai.2017.08.012 
[8] Derendorf H, Meltzer EO. Molecular and clinical pharmacology of intranasal corticosteroids: Clinical and therapeutic implications. Allergy 2008; 63: 1292-1300. https://doi.org/10.1016/j. anai.2017.08.012

[9] European Medicines Agency: Committee for Medicinal Products for Human Use (2013) Assessment report: Fluticasone furoate and vilanterol (Procedure No. EMEA/H/C/002673/0000); http://www.ema. europa.eu/docs/en_GB/document_library/EPAR_-_Public_assessment_report/human/002673/WC500157635.pdf. Accessed 29 December 2019

[10] Allen A, Down G, Newland A et al. Absolute bioavailability of intranasal fluticasone furoate in healthy subjects. Clin Ther 2007; 29: 1415-1420. https://doi.org/10.1016/j.clinthera.2007.07.028

[11] Martin BG, Ratner PH, Hampel FC et al. Optimal dose selection of fluticasone furoate nasal spray for the treatment of seasonal allergic rhinitis in adults and adolescents. Allergy Asthma Proc 2007; 28: 216-225. https://doi.org/10.2500/aap.2007.28.2983

[12] Bridgeman MB. Overcoming barriers to intranasal corticosteroid use in patients with uncontrolled allergic rhinitis. Integr Pharm Res Pract 2017; 6: 109-119. https://doi.org/10.2147/IPRP.S129544
[13] Brozek JL, Bousquet J, Baena-Cagnani CE et al.Global Allergy and Asthma European Network; Grading of Recommendations Assessment, Development and Evaluation Working Group Allergic Rhinitis and its Impact on Asthma (ARIA) guidelines: 2010 revision. J Allergy Clin Immunol 2010; 126: 466-476. https://doi.org/10.1016/j. jaci.2010.06.047

[14] Brożek JL, Bousquet J, Agache I et al. Allergic Rhinitis and its Impact on Asthma (ARIA) guidelines-2016 revision. J Allergy Clin Immunol 2017; 140: 950-958. https://doi.org/10.1016/j.jaci.2017.03.050

[15] Lipworth B, Newton J, Ram B et al. An algorithm recommendation for the pharmacological management of allergic rhinitis in the UK: $A$ consensus statement from an expert panel. NPJ Prim Care Respir Med 2017; 27: 3

[16] Food and Drug Administration: Center for Drug Evaluation and Research (2007) Application number 22-051: Clinical pharmacology and biopharmaceutics review(s). https://www.accessdata.fda.gov/ drugsatfda_docs/review/2018/022051Orig1s017.pdf, Accessed 29 December 2019 